\title{
Research of primary hyperhidrosis in students of medicine of the State of Sergipe, Brazil ${ }^{*}$
}

\author{
Sônia Oliveira Lima ${ }^{1,2}$ \\ José Machado Neto ${ }^{2}$ \\ Layla Melize Santos Menezes ${ }^{1}$
}

\author{
João Fernandes Britto Aragão ${ }^{2}$ \\ Kaio Bernardes Santos de Almeida ${ }^{2}$ \\ Vanessa Rocha Santana ${ }^{1,3}$
}

DOI: http:/ / dx.doi.org/10.1590/abd1806-4841.20153859

\begin{abstract}
BACKGROUND: Hyperhidrosis or excessive sweat production occurs at 2.9-9\% of the population. Овлестіvе: To estimate the prevalence and disorders due to primary hyperhidrosis (HP) in medicine students in the state of Sergipe.

Methods: Cross-sectional study using individual interviews.

RESULTS: Hyperhidrosis was found in $14.76 \%$ of subjects, the most affected regions were palmar, plantar and axillary, causing prejudice in daily activities. Family history occurred in $45 \%$ and $22.72 \%$ was diagnosed by a physician.

CONCLUSION: The prevalence of hyperhidrosis in medicine students of Sergipe was high, with strong family and a small portion of diagnoses made by medical professionals.
\end{abstract}

Keywords: Hyperhidrosis; Epidemiology; Sweat; Students, medical

\section{INTRODUCTION}

Hyperhidrosis is a disorder defined as excessive sweat production by the body beyond what is required by homeostasis. ${ }^{1}$ It can be classified as primary $(\mathrm{PH})$ or secondary hyperhidrosis (SH). HP has no known cause and is characterized by excessive sweating due to hyperactivity of the sympathetic nervous system that innervate the sweat glands. HP manifests focally in usually symmetrical anatomical regions such as armpits, palms, soles, face and other areas. When excessive transpiration has a known cause, it is classified as $\mathrm{SH}$ whose etiology may be due to a variety of factors such as infection, malignancy, drugs, anxiety and neurological and endocrine disorders. ${ }^{2}$
Some studies show a familiar component in $\mathrm{PH}$, suggesting autosomal dominant inheritance of variable penetration for this disorder. ${ }^{3}$ In addition, there is also a climate and emotional influence in patients with this condition. ${ }^{4}$ The affection has no association with gender, although it occurs in overweight and obese. ${ }^{1,4,5}$ Among the therapeutic options for HP, antiperspirants, iontophoresis, botulinum toxin injection or surgical treatment are used. The main representative of the surgery is endoscopic sympathectomy, considered the gold standard for the possibility of $\mathrm{HP}^{\prime}$ s permanent cure. ${ }^{6,7}$ 
Epidemiological studies have found a $\mathrm{PH}$ prevalence ranging from $2.9 \%$ to $9 \%$ in the populations studied; therefore, this disease is not a rare event. ${ }^{1,2,4,5}$ There is a negative impact on patient's life, causing limitations in occupational, educational, social, physical and leisure activities. ${ }^{1,7}$ The magnitude of the losses in quality of life is comparable to conditions such as severe psoriasis, kidney failure and endstage rheumatoid arthritis. ${ }^{8}$ Moreover, patients with hyperhidrosis has a higher prevalence of anxiety than that described in the general population and in patients with other chronic diseases. ${ }^{9}$ Nevertheless, HP is still underdiagnosed by health professionals and few studies assess its prevalence. ${ }^{7,10}$ In Northeast, Southeast and Midwest of Brazil, there are no studies that contemplate this disease.

The aim of this study is to estimate the prevalence and consequent disorders due to $\mathrm{PH}$ in medicine students in the State of Sergipe, located in Northeastern region of Brazil, as well as assess the most affected anatomical regions, the presence of family history and the percentage of HP diagnosis given by a physician.

\section{METHODS}

This is a cross-sectional study. Population considered for the sample size calculation of the research was medicine students from the Universidade Federal de Sergipe (UFS, campus and University Hospital) and Universidade Tiradentes (UNIT), both in the State of Sergipe. For the assignment of the total of students, it was requested to Academic Directories of these institutions the number of students enrolled in all periods of the related course in the second semester of 2011, resulting in 760 individuals. Of this total, 107 students were from UNIT (a private institution) and 653 from UFS (a public institution). Based on a previous study by Strutton et al ${ }^{1}$, which estimated a population prevalence of $\mathrm{PH}$ of $2.9 \%$, a probability sample was calculated, considering an error of $5 \%$ and an accuracy of 1\%, resulting in a sample of 447 students. Participants were randomly defined by statistical program BioEstat 5.0.

\section{Collection procedures and data analysis}

Data collection was made through individual interviews in private, air-conditioned environment with a questionnaire for students applied by academic staff, previously trained to complete the protocol. The questionnaire was structured with closed and open questions, addressing issues such as gender, date of birth, color, age of onset of symptoms, affected sites, diagnostic criteria and psychological, study, work and social disorders caused by $\mathrm{PH}$, besides questioning if the patient consulted any health professional. ${ }^{11}$ For the diagnosis, we considered the study by Haider et al 11, which defines as $\mathrm{PH}$ the positive answer to the first question and the presence of positive reaction to at least two questions (Chart 1). Medicine students who agreed to participate in the study were included in the research after signing the informed consent (IC).

The study was performed in accordance with the recommendations of the Helsinki Declaration of 1989 and the Resolution 196/96 on research involving human subjects from the National Health Council and was approved by CONEP's ethics committee under the number 260511.

Collected data were entered into a spreadsheet using Microsoft Excel 2007. Results were analyzed using descriptive statistics of data through mean, absolute and relative frequencies. Analysis was inferential by chi-square test for categorical variables. We considered the significance level of $5 \%(\mathrm{p}<0.05)$.

\section{RESULTS}

The study enrolled 447 medicine students of the State of Sergipe, 63 of them (14.09\%) from UNIT and $384(85.91 \%)$ from UFS. Of these, $225(50.34 \%)$ were men and $222(49.66 \%)$ were women, with age ranging from 18 to 52 years old (mean 23.04; SD=3.808). Participants were: 191 (42.74\%) white; 232 (51.9\%) brown; and 24 (5.36\%) black.

Sixty-six participants declare to have HP, with a prevalence of $14.76 \%$ (66/447): 10 (15.15\%) from UNIT and $56(84.85 \%)$ from UFS. Of these, $39(59.09 \%)$ were men and $27(40.91 \%)$ were women, with no statistical difference between genders $(p=0.123)$. The age of onset of PH were: 0 to 5 years (3.03\%); 5 to 10 years $(16.67 \%)$; 10 to 15 years $(31.82 \%) ; 15$ to 20 years $(39,40 \%) ; 20$ to $25(7.58 \%)$; and over 26 years $(1.5 \%)$. Anatomical regions affected by $\mathrm{PH}$ were: palmar (39.62\%); plantar (25.47\%); axillary (22.65\%); facial $(9.43 \%)$; and cranial $(2.83 \%)$. Diagnosis was made by a physician in 15 patients $(22.72 \%)$. Familial relation with $\mathrm{PH}$ was reported by $30(45 \%)$ participants (Table 1$)$. Regarding skin color declared by the interviewees, the disease affected 24 whites (36.37\%); 41 browns (62.21\%); and one black $(1.42 \%)$, not finding significant differences referring to $\mathrm{PH}(\mathrm{p}=0.109)$.

In $47(71.21 \%)$ of patients with the disease, the episode of excessive sweating occurs at least once during the week; in $50(75.76 \%)$, excessive sweating is bilateral; $52(78.79 \%)$ states that the aggravation of the condition is related to stress (Table 1). Of the participants, $25(37.9 \%)$ claimed some sort of impairment in daily activities, whether in mental, study, work or social order (Graph 1). 
Chart 1: Questionnaire

Place where the study was carried out:

Gender: [ [ ] Male [ ] Female _ Date of Birth: __ _ _ _ _ A Age: $($ ) years

Diagnostic criteria for primary idiopathic hyperhidrosis:

a) Is there excessive sweating, localized and visible, for at least six months and without any apparent cause?

[ ]yes [ ] no

b) Place where excessive sweating is present
[ ] head
[ ] face
[ ] palmar
[ ] axillae [ ] plantar

c) In addition, two more of the characteristics listed below are present:

[ ] bilateral and relatively symmetrical

[ ] frequency of at least once a week

[ ] compromised activities of daily living
( ) psychological
( ) academic ( ) social
( ) occupational

[ ] age at onset under 25 years (if positive, indicate below)
( ) 0 - 5 years
( ) 15 - 20 years
( ) 5 - 10 years( ) $20-25$ years
( ) $10-15$ years

years or more

[ ] positive family history

[ ] sweating interrupted during sleep

[ ] worsening in stressful situations

[ ] little or no interference of temperature

d) Were you diagnosed by a health professional?
[ ] yes
[ ] no

TABle 1:Variables studied in HP

\begin{tabular}{|c|c|c|}
\hline PH & $\begin{array}{l}\text { Absolute } \\
\text { frequency }\end{array}$ & $\begin{array}{l}\text { Relative } \\
\text { frequency }\end{array}$ \\
\hline Positive family history & 30 & $45 \%$ \\
\hline Medical diagnosis & 15 & $22.72 \%$ \\
\hline $\begin{array}{l}\text { More than one episode } \\
\text { per week }\end{array}$ & 47 & $71.21 \%$ \\
\hline Bilateral & 50 & $75.76 \%$ \\
\hline Worsened by stress & 52 & $78.79 \%$ \\
\hline Activities impairment & 25 & $37.9 \%$ \\
\hline
\end{tabular}

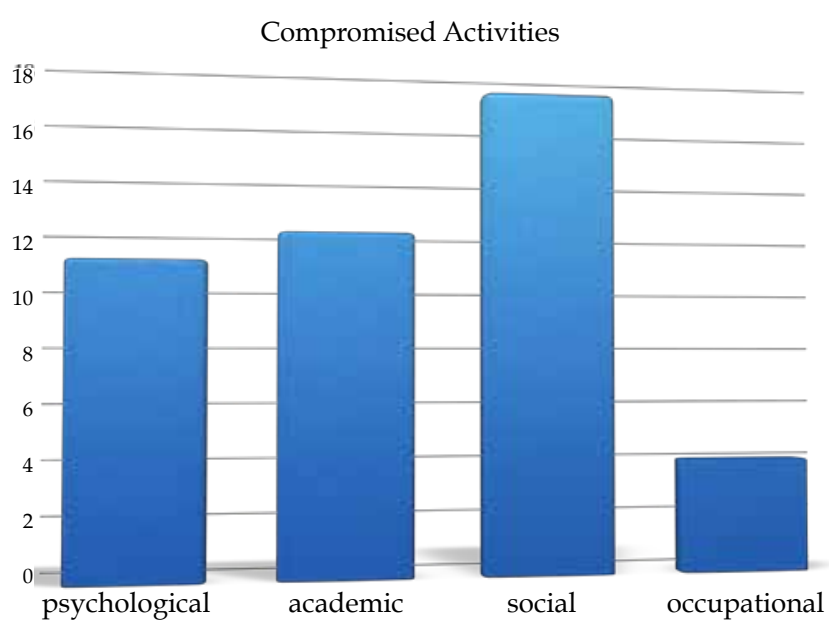

Graph 1: Absolute Frequency of Compromised Activities of Daily Living triggered by $\mathrm{PH}$ 


\section{DISCUSSION}

Strutton et al ${ }^{1}$ conducted a study in the United States by sending letters with survey to 150,000 homes, which revealed a prevalence of $\mathrm{PH}$ in $2.9 \%$ of the study population, equivalent to 7.8 million people. The reported prevalence in 3 cities in southwest China, using a self-administered questionnaire with a sample of 33,000 people was $4.36 \% .{ }^{5}$ Augustin et al ${ }^{12}$ in a study in Germany during individual dermatological examination with 14,336 adults, questioned about the occurrence of focal hyperhidrosis, finding a prevalence of $16.3 \%$. A study performed by Fenili et $\mathrm{al}^{2}$ in Brazil, using Haider et al ${ }^{11}$ diagnostic criteria with individual interviews, found a prevalence of $9 \%$. In this study, the frequency of $\mathrm{PH}$ found was $14.57 \%$, which allows to emphasize the importance of this disorder in medicine students in the State of Sergipe. The prevalence of $\mathrm{HP}$ varied depending on the population studied and on the methodology applied. It is noteworthy that a higher prevalence was observed when the interviews were conducted presentially, individually and by specialized personnel.

In studies with general population, Park et al ${ }^{13}$ found that the onset of symptoms occurred at mean age of 15 years. Fenili et $\mathrm{al}^{2}$ showed that $55.55 \%$ of the population with $\mathrm{PH}$ noticed symptoms before 25 years old. This study gathered similar data, with $39.40 \%$ of the beginning of PH occurring between 15 and 20 years old. This is an important factor because this age group is marked by intense need to establish interpersonal relationships, to play sports and to perform work activities, and the development of these activities can be seriously affected by this disease.

Studies by Struton et $\mathrm{al}^{1}$ and Fenili et al ${ }^{2}$ didn't show significant difference between genders in $\mathrm{PH}^{\prime} \mathrm{s}$ involvement, what was also found among medicine students in the State of Sergipe. Lear et al, analyzing the US population, noted that $\mathrm{PH}$ affected $87.9 \%$ Caucasians, $8.4 \%$ African Americans, $1.7 \%$ Asians, $0.8 \%$ Hispanics, and $0.8 \%$ Indians. $^{14}$ This ethnic distribution was similar to that found in the present study, which showed whites and browns with greater frequency of $\mathrm{PH}$ among medicine students.

Park et al ${ }^{13}$, Fenili et $\mathrm{al}^{2}$, Lear et $\mathrm{al}^{14}$ and Westphal et al ${ }^{4}$ verified, respectively, presence of positive family history in $34.1 \%, 43.7 \%, 44.44 \%$ and $50 \%$ of $\mathrm{PH}$ patients in their study. Other studies have suggested an autosomal dominant component of variable penetration for this disorder. ${ }^{3}$ This study identified the family influence in $45 \%$ of participants with $\mathrm{PH}$, according to the literature previously cited.

Lear et $\mathrm{al}^{4}$ found that axillary region was the most affected by HP (73\%) and exceeded palmar $(45.9 \%)$ and plantar $(41.1 \%)$ areas. Park et al ${ }^{13}$, in turn, showed that palmar and plantar sites simultaneously were the most frequent, accounting for $32.2 \%$ of the sample. Westphal et $\mathrm{al}^{4}$ concluded that palmar $\mathrm{PH}$ was the most frequent form (36\%), before plantar $\mathrm{PH}(21 \%)$ and axillary $\mathrm{PH}(18 \%)$. Among medicine students from Sergipe, palmar $\mathrm{PH}$ accounted for $39.62 \%$ of cases, followed by plantar $(25.47 \%)$, axillary $(22.65 \%)$, facial $(9.43 \%)$ and cranial $(2.83 \%) \mathrm{PH}$. In $75.76 \%$ of participants, excessive sweating was bilateral. This diversity may be due to the age of the population of this study: it is known that palmar and plantar $\mathrm{PH}$ begins earlier than axillary and facial $\mathrm{PH} .{ }^{14}$

Medicine students have different motivations and expectations about the medical profession since the beginning of the course, which will be polished with difficulties, disappointments and rewards along the graduation. ${ }^{15}$ These situations can trigger excessive sweating and cause embarrassment before their colleagues, professors, other health professionals and patients. In the present study, students mentioned psychological, study, work and social disorders due to this condition. $\mathrm{PH}$, regardless of its sites, can difficult or even preclude these patients to perform some procedures, interfering with their career choice. Medicine students, for example, need in their practical activities greet by shaking hands, examine patients, handle tests, prescribe in the medical records, issue receipts, wear gloves, handle tools and computers, etc. These activities can become difficult because of the intense sweat on the palms, sometimes causing the patient to interpret it as nervousness of who is examining. In relation to axillary $\mathrm{PH}$, people can interpret as carelessness or poor hygiene of the patient, especially when accompanied by bromohidrosis (foul odor). As for facial $\mathrm{PH}$, dripping sweat may spill into the patient to be examined or even during surgery, contaminating the surgical field.

Although PH is not a rare disorder and it has very negative impacts on the life of patients, only $22.72 \%$ of medicine students in the State of Sergipe were diagnosed by a physician. ${ }^{16}$ This fact is probably due to the small value or little knowledge of this impairment by health professionals.

\section{CONCLUSION}

Prevalence of $\mathrm{PH}$ in medicine students in the State of Sergipe is high. The most frequent age of onset of symptoms was 15 to 20 years, with no difference between genders or interference of skin color, but with strong family character. The most affected sites were palmar and plantar regions, followed by axillary region. PH was rarely diagnosed by a physician although, in this study, patients are medicine students, who participate in health care activities and report psychical, work, study and social impairment. 


\section{REFERENCES}

1. Strutton DR, Kowalski JW, Glaser DA, Stang PE. US prevalence of hyperhidrosis and impact on individuals with axillary hyperidrosis: results from a national survey. J Am Acad Dermatol. 2004;51:241-8.

2. Felini R, Demarchi AR, Fistarol ED, Matiello M, Delorenze LM. Prevalence of hyperhidrosis in the adult population of Blumenau-SC, Brazil. An Bras Dermatol. 2009; 84:361-6.

3. Yamashita N, Tamada Y, Kawada M, Mizutani K, Watanabe D, Matsumoto Y. Analysis of family history of palmoplantar hyperhidrosis in Japan. J Dermatol. 2009;36:628-31.

4. Westphal FL, Carvalho MANC, Lima LC, Carvalho BCN, Padilla R, Karla K, et al. Prevalência de hiperidrose entre estudantes de medicina. Rev Col Bras Cir. 2011;38:392-7.

5. Li X, Chen R, Tu YR, Lin M, Lai FC, Li YP, et al. Epidemiological survey of primary palmar hyperhidrosis in adolescents. Chin Med J (Engl). 2007;120:2215-7.

6. Wolosker N, de Campos JR, Kauffman P, de Oliveira LA, Munia MA, Jatene FB. Evaluation of quality of life over time among 453 patients with hyperhidrosis submitted to endoscopic thoracic sympathectomy. J Vasc Surg. 2012;55:154-6.

7. Reis GMD, Guerra ACS, Ferreira JPA. Estudo de pacientes com hiperidrose, tratados com toxina botulínica: análise retrospectiva de 10 anos. Rev Bras Cir Plást. 2011;26:582-90.

8. Hoorens, I, Ongenae K. Primary focal hyperhidrosis: current treatment options and a step-by-step approach. J Eur Acad Dermatol Venereol. 2012;26:1-8.

9. Bragança GM, Lima SO, Pinto Neto AF, Marques LM, Melo EV, Reis FP. Evaluation of anxiety and depression prevalence in patients with primary severe hyperhidrosis. An Bras Dermatol. 2014;89:230-5.

10. Vorkamp T, Foo FJ, Khan S, Schmitto JD, Wilson P. Hyperhidrosis: evolving concepts and a comprehensive review Surgeon. 2010;8:287-92.

11. Haider A, Solish N. Focal hyperhidrosis: diagnosis and management. CMAJ. 2005 Jan 4;172(1):69-75.

12. Augustin M, Radtke MA, Herberger K, Kornek T, Heigel H, Schaefer I. Prevalence and Disease Burden of Hyperhidrosis in the Adult Population. Dermatology. 2013;227:10-3.

13. Park EJ, Han KR, Choi H, Kim do W, Kim C. An epidemiological study of hyperhidrosis patients visiting the Ajou University Hospital Hyperhidrosis Center in Korea. J Korean Med Sci. 2010;25:772-5.

14. Lear W, Kessler E, Solish N, Glaser DA. An epidemiological study of hyperhidrosis. Dermatol Surg. 2007;33:S69-75.

15. Trindade LMDF, Vieira MJ. Curso de medicina: motivações e expectativas de estudantes iniciantes. Rev Bras Educ Med. 2009; 33:542-54.

16. Stefaniak T, Cwigon M, Łaski D. In the Search for the Treatment of Compensatory Sweating. ScientificWorldJournal. 2012;2012:134547.
MAILING ADDRESS:

José Machado Neto

650, Pedro Valadares Avenue, 650 - Apt. 603

49025-090 - Aracaju - SE

Brazil

Email:machado.jmn@live.com

How to cite this article: Lima SO, Aragão JFB, Machado Neto J, Almeida KBS, Menezes LMS, Santana VR. Research of primary hyperhidrosis in students of medicine of the state of Sergipe, Brazil An Bras Dermatol. 2015;90(5):661-5. 